\title{
Stable Properties of Spontaneous EPSCs and Miniature Retinal EPSCs during the Development of ON/OFF Sublamination in the Ferret Lateral Geniculate Nucleus
}

\author{
Carsten D. Hohnke and Mriganka Sur \\ Department of Brain and Cognitive Sciences, Massachusetts Institute of Technology, Cambridge, Massachusetts 02139
}

Retinal projections to the lateral geniculate nucleus (LGN) in ferrets progressively segregate into eye-specific laminae and subsequently into sublaminae that receive inputs from either ON-center or OFF-center afferents. To study the development of synaptic efficacy during a period of activity-dependent growth and reorganization in the CNS, we recorded spontaneous EPSCs (sEPSCs) from cells of the LGN during ON/OFF sublamination. We also examined retinal inputs specifically by stimulating the optic tract in the presence of strontium and recording evoked miniature EPSCs (emEPSCs). The rise times, areas, half-widths, and decay times of sEPSCs and emEPSCs and interevent intervals of sEPSCs recorded the beginning of ON/OFF sublamination were not different from those recorded after its completion. Typically EPSC areas were small (10-20 fC) but varied greatly both within and between neurons. The frequency of sEPSCs was also quite variable, ranging from 0.2 to $5 \mathrm{~Hz}$. sEPSCs were equivalent to miniature EPSCs recorded in the presence of tetrodotoxin, and both sEPSCs and emEPSCs were CNQX-sensitive. No difference was observed between sEPSCs recorded at room temperature and those recorded at $34^{\circ} \mathrm{C}$, and strontium could be substituted for calcium with no effect on sEPSC shape. These data argue for a remarkable stability in the components of at least AMPA-mediated synaptic transmission during a period of major synaptic rearrangement in the LGN.

Key words: activity-dependent; pattern formation; AMPAsynapse; retinal axons; LTP; visual system
The development of precise connectivity in the mammalian visual system depends on normal neural activity (for review, see Goodman and Shatz, 1993; Cramer and Sur, 1995; Katz and Shatz, 1996). For example, the segregation of left and right eye inputs in the visual cortex is disrupted after neonatal lid suture (Sherman and Spear, 1982) or intraocular injections of tetrodotoxin (TTX) (Stryker and Harris, 1986). Activity is also crucial to the development of the appropriate wiring in structures involved in earlier stages of visual processing. In the ferret, retinogeniculate axons from the two eyes segregate during development to form eye-specific layers (Linden et al., 1981). Subsequently, within each of the eye-specific layers, inputs from ON-center and OFF-center retinal ganglion cells segregate to form sublaminae (Stryker and Zahs, 1983; Hahm et al., 1991). Segregation of retinal inputs into eye-specific laminae is modulated by activity (Shatz and Stryker, 1988; Cook et al., 1996; Penn et al., 1998), and the segregation into ON/OFF sublaminae is disrupted entirely by intraocular TTX injections (Cramer and Sur, 1997), inactivation of NMDA receptors (Hahm et al., 1991), or nitric oxide blockade (Cramer et al., 1996).

Not only is normal neural activity critical for appropriate retinogeniculate axon development, it is also involved in the development of its major postsynaptic target, the relay cells of the lateral geniculate nucleus (LGN). When D-APV, an NMDA re-

\footnotetext{
Received May 29, 1998; revised Oct. 16, 1998; accepted Oct. 16, 1998.

This work was supported by National Institutes of Health Grants EY 11512 and EY 07023. We thank Guosong Liu for valuable discussion and comments on this manuscript and Joseph Locascio for assistance with statistical analyses. We also thank two anonymous referees for their comments.

Correspondence should be addressed to Mriganka Sur, Massachusetts Institute of Technology, E25-235, 45 Carleton Street, Cambridge, MA 02139.

Copyright (C) 1998 Society for Neuroscience $0270-6474 / 98 / 190236-12 \$ 05.00 / 0$
}

ceptor antagonist, is infused into the thalamus during the third postnatal week, LGN relay cells show an increase in dendritic branching and the number of dendritic spines (Rocha and Sur, 1995). Likewise, intracranial infusions of TTX in fetal cats cause an increase in the density of dendritic spines (Dalva et al., 1994). Later in development, after eye opening, the normal elimination of transient dendritic spines is delayed after early eye enucleation (Sutton and Brunso-Bechtold, 1993).

Activity-dependent development of connections in the visual system has components that seem to be shared with long-term potentiation (LTP) of synapses in the CA1 region of the hippocampus (Shatz, 1990; Goodman and Shatz, 1993; Cramer and Sur, 1995). For example, both phenomena require electrical activity but may also require NMDA receptor activation, nitric oxide production (Bliss and Collingridge, 1993), and neurotrophin signaling (Cabelli et al., 1995; Kang and Schuman, 1995). Consequently, it has been suggested that LTP and its counterpart, long-term depression, underlie the stabilization and withdrawal of synapses in developing sensory structures (Constantine-Paton et al., 1990; Kandel and O'Dell, 1992; Goodman and Shatz, 1993; Cramer and Sur, 1995; Katz and Shatz, 1996; Constantine-Paton and Cline, 1998). A similar mechanism may operate at the neuromuscular junction where changes in connectivity are preceded by experience-driven changes in synaptic efficacy (Colman et al., 1997). Yet, exactly how changes in the wiring between two neurons are reflected by changes in synaptic transmission between them is not well understood.

There is, however, a growing body of evidence that suggests that NMDA receptor-mediated activity plays an important role in initiating the stabilization of appropriate inputs during development (for review, see Hofer et al., 1994; Cramer and Sur, 1995; Constantine-Paton and Cline, 1998). NMDA receptors undergo 


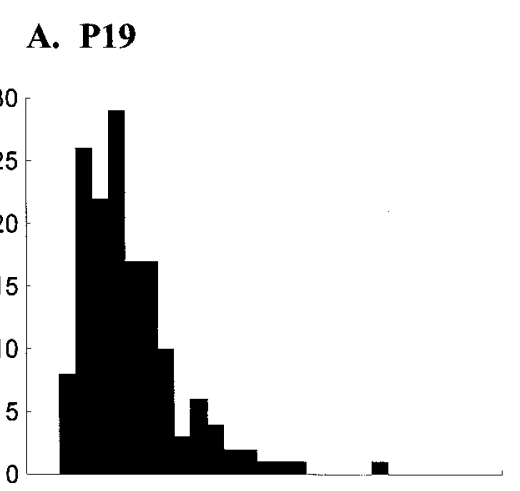

B. P30

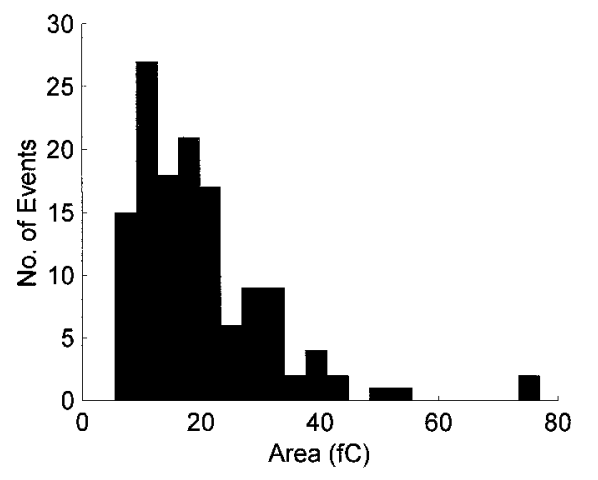

developmental changes in their subunit composition in several regions of the nervous system (for review, see Scheetz and Constantine-Paton, 1994) that coincide with decreases in NMDA-mediated currents at the end of periods of axonal reorganization (Ramoa and Prusky, 1997; Shi et al., 1997). The longer duration of NMDA receptor-mediated responses at immature synapses may facilitate the induction of a form of LTP expressed as an increase in the effectiveness of AMPA responses (Constantine-Paton and Cline, 1998).

As a first step toward examining changes in AMPA-mediated synaptic transmission during a period of activity-dependent, axonal reorganization in the CNS, we have recorded spontaneous EPSCs (sEPSCs) and optic tract-evoked miniature EPSCs (emEPSCs) in brain slices from ferrets of varying ages during the period of ON/OFF sublamination in the LGN; at the retinogeniculate synapse sEPSCs have been shown to be quantal and equivalent to mEPSCs (Paulsen and Heggelund, 1994). In the LGN dramatic changes in connectivity are thought to be occurring during ON/OFF sublamination. Retinal axons are refined in an activity-dependent manner during the third and fourth postnatal weeks (Cramer et al., 1996; Cramer and Sur, 1997). Anatomical data from the cat suggest that the number of retinal synapses on LGN cells increases by $\sim 25 \%$ during the first 8 weeks postnatally (Kalil and Scott, 1979; Mason 1982), whereas the number of cortical inputs increases eightfold during the first 10 weeks (Weber and Kalil, 1987). In addition to changes in NMDA receptor-mediated current and a possible increase in the efficacy of AMPA synapses, it is possible that developmental changes in the subunit composition of AMPA receptors occur during ON/ OFF sublamination as they do in other regions of the nervous system (Durand and Zukin, 1993; Rossner et al., 1993; Jakowec et al., 1995). Thus, there are a number of reasons to expect changes in sEPSCs and emEPSCs over this period.
Figure 1. $\quad$ SEPSC areas in the LGN are stable during ON/OFF sublamination. Histograms of sEPSC areas and example current traces from a $\mathrm{P} 19(A)$ and a P30 $(B)$ neuron are shown. Histograms for all properties measured were skewed toward larger values and showed considerable variability. The bottom traces for each neuron are averages of 50 consecutive sEPSCs.
Surprisingly, we find no change in the properties of AMPAmediated spontaneous and miniature retinal EPSCs over the period of ON/OFF sublamination. These data have interesting implications for activity-dependent development of retinogeniculate synapses.

Preliminary reports have been published in abstract form (Hohnke and Sur, 1996, 1998).

\section{MATERIALS AND METHODS}

Whole-cell patch-clamp recordings (Blanton et al., 1989) were made during voltage clamp of LGN relay cells in thalamic slices (400 $\mu \mathrm{m}$ thick) from young [postnatal day 12 (P12) to P31] ferrets. The animals were deeply anesthetized with sodium pentobarbital $(35 \mathrm{mg} / \mathrm{kg}$, i.p.) and decapitated. A block of tissue including the thalamus was rapidly removed and placed in a cold solution $\left(4^{\circ} \mathrm{C}\right)$ containing (in $\mathrm{mm}$ ): $\mathrm{NaCl}$ (126), $\mathrm{KCl}(3), \mathrm{MgSO}_{4}(2), \mathrm{NaHCO}_{3}$ (25), $\mathrm{NaHPO}_{4}$ (1), $\mathrm{CaCl}_{2}$ (2.5), and dextrose (10), saturated with $95 \% \mathrm{O}_{2}$ and $5 \% \mathrm{CO}_{2}, \mathrm{pH}$ 7.4. In some experiments $\mathrm{NaCl}$ was replaced with equiosmolar sucrose $(252 \mathrm{~mm}$; Aghajanian and Rasmussen, 1989), and kynurenic acid (0.5 mM) was added to minimize excitotoxicity during slicing. The cortex was dissected away, and the remaining thalamus was sliced in the horizontal or coronal plane with a Vibratome (Ted Pella model 1000).

In most experiments, slices were maintained at room temperature and continuously superfused with the NaCl-based solution described above (control medium). In some experiments $50 \mu \mathrm{M}$ bicuculline methiodide (BMI; Sigma Chemical Co., St. Louis, MO), $1 \mu \mathrm{M}$ tetrodotoxin (TTX, Sigma), and/or $10 \mu \mathrm{M}$ 6-cyano-7-nitroquinoxaline-2,3-dione (CNQX disodium; Research Biochemicals, Natick, MA) was added to the control medium. In a few experiments the calcium was replaced with strontium (1-3 mM). Before "blind" recording, a slice was transferred to an interface-type chamber and given $45 \mathrm{~min}$ to equilibrate to $34^{\circ} \mathrm{C}$. In later experiments slices were transferred to a submersion chamber, and recordings were performed at room temperature under visual control with differential interference contrast-enhanced optics. In both cases, the boundaries of the LGN and the position of the recording electrode were visible, and recordings were made in the A or A1 lamina.

Retinal afferents were stimulated by delivering constant current through a bipolar stimulating electrode positioned in the optic tract at the 
lateral edge of the slice. Electrical stimuli, averaging $5 \mathrm{~mA}$ for $0.02 \mathrm{msec}$, were delivered at $0.5 \mathrm{~Hz}$, and emEPSCs were detected (as described below) during the $1 \mathrm{sec}$ period after the synchronous response. Stimulus strength was set at a value slightly greater than the value that produced the minimal response.

Patch pipettes were pulled from borosilicate glass (World Precision Instruments) on a horizontal pipette puller (Sutter Instruments) to tip resistances of 3-8 $\mathrm{M} \Omega$. The pipettes were filled with (in $\mathrm{mM}$ ): potassium gluconate (125), $\mathrm{KCl}(10), \operatorname{HEPES}(10)$, sodium EGTA (1), $\mathrm{CaCl}_{2}(0.1)$, $\mathrm{MgCl}_{2}$ (2), Na-ATP (2), and Na-GTP (0.2) or cesium gluconate (120), HEPES (10), sodium EGTA (1), $\mathrm{CaCl}_{2}(0.1), \mathrm{MgCl}_{2}$ (2), Na-ATP (2), and Na-GTP (0.1); the $\mathrm{pH}$ was adjusted to 7.3. Recordings were obtained with an Axopatch-200 amplifier (Axon Instruments), digitized using a Neurocorder encoding unit (Neurodata), and stored on video tape and computer disk for off-line analysis. Access resistance was monitored throughout the experiment but not compensated for. Recordings that varied by $>20 \%$ were not analyzed. Data were acquired off-line with the pClamp data acquisition software (Axon Instruments) and analyzed using Matlab (MathWorks). Cells were voltage-clamped at $-60 \mathrm{mV}$. Cells that showed overshooting action potentials and that had resting membrane potentials more hyperpolarized than $-40 \mathrm{mV}$ were considered for analysis. Recordings used for analysis had series resistances $<33$ $\mathrm{M} \Omega$. sEPSCs and emEPSCs were automatically detected (using a threshold of 1.5-2.5 times the SD of the noise) below a moving average of the current and were reviewed by visual inspection to eliminate noiseinduced detections. The events were fit using a least squares algorithm with the sum of three (one rising and two decaying) exponentials (Soltesz and Mody, 1995). Area was calculated by integrating the fitted curve between the beginning and end of the event. Rise times were calculated from 20 to $80 \%$, widths at $50 \%$, and decay times at $e^{-1}$ of peak amplitude. Recordings from animals P29 and older (when ON/OFF sublamination is complete), termed the "older" group, were compared with recordings from P12-P24 animals (when ON/OFF sublaminae are actively segregating within eye-specific layers), termed the "younger" group.

Five types of nonparametric statistical analyses were performed, because none of the data appeared to be normally distributed, and, given the highly skewed nature of the distributions, median values were used as the preferred measure of central tendency. Spearman's rank correlation was used to test for significant correlations. Median parameter values between groups were compared with the Mann-Whitney $U$ test, or, if the number of groups was more than two (e.g., when testing for interactions between intracellular solution and age), with the Kruskal-Wallis nonparametric ANOVA. Parameter distributions from different conditions within the same recording were compared with the Kolmogorov-Smirnov test. Finally, the Siegel-Tukey test was used to determine whether the variance of median parameter values was different for the two groups. Values are presented as medians (mean \pm SDs). In Figures $2 B$ and $8 B$, values are expressed as SDs from the mean to allow the pooling of events across cells (Hsia et al., 1998). To represent the younger and older groups in the pool equally, 50 randomly selected events were chosen from an equal number of the youngest cells and oldest cells for which there were at least 50 events.

\section{RESULTS}

\section{Spontaneous EPSCs}

Spontaneous EPSCs were analyzed in 32 cells from animals between P12 and P31. sEPSCs were observed in $\sim 66 \%$ of the cells and were recorded from animals at all ages throughout the period of sublamination. We observed no correlation between the age at which recordings were made and the observation of sEPSCs. We recorded 2222 sEPSCs from younger animals and 739 sEPSCs from older animals. Typical distributions of areas and the averaged sEPSC for one younger and one older cell are shown in Figure 1. The histograms show skewed distributions that were observed at all ages for all sEPSC parameters measured and are similar to those seen in other regions of the brain, including the hippocampus (McBain and Dingledine, 1992, 1993; Jonas et al., 1993) and cerebral cortex (Hestrin 1992, 1993; Stern et al., 1992). Pooled data from 10 of the youngest and 10 of the oldest cells show sEPSC area and interevent interval (IEI) histograms that
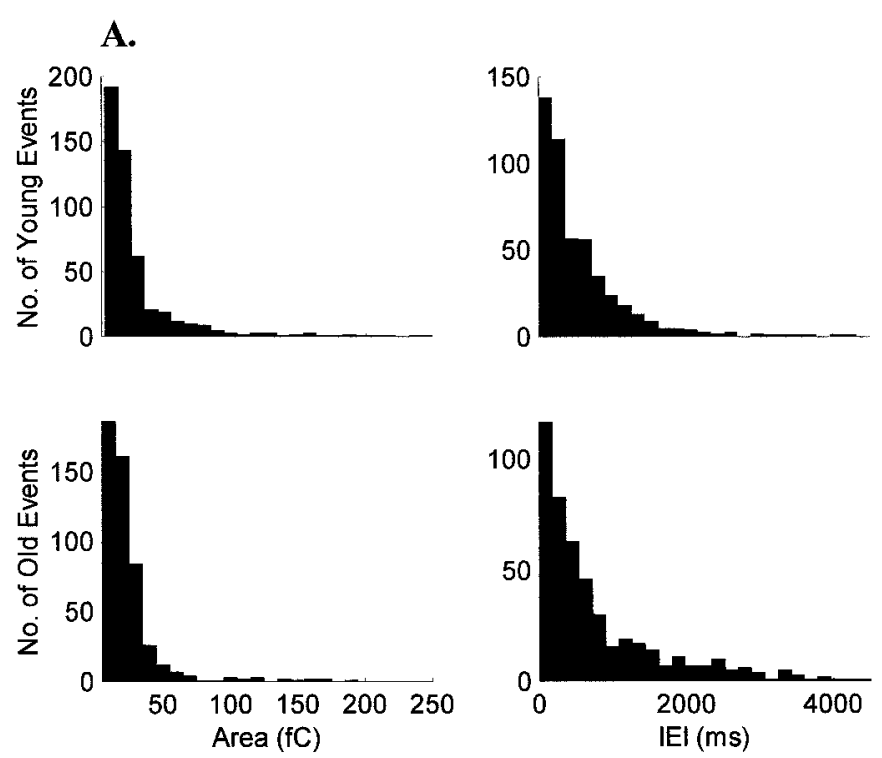

B.
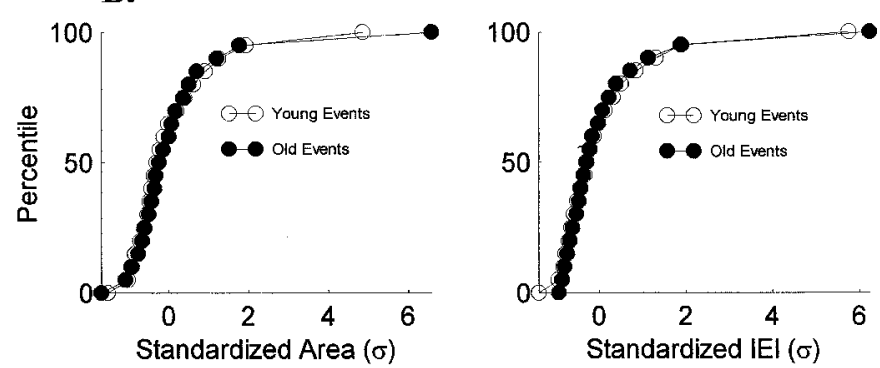

Figure 2. The shape of sEPSC area and IEI distributions is stable over $\mathrm{ON} / \mathrm{OFF}$ sublamination. $A$, Histograms of pooled data from the youngest cells $(n=10)$ and the oldest cells $(n=10)$ are similar for both sEPSC area and IEIs. $B$, Cumulative histograms of the standardized areas and IEIs show that the shapes of the distributions did not change with age $(p>$ 0.05, Kolmogorov-Smirnov test).

are similar (Fig. $2 A$ ). Indeed, the shapes of the distributions were the same for the two groups $(p>0.05$, Kolmogorov-Smirnov test; Fig. $2 B$ ), as were the distributions for rise, width, and decay times $(p>0.05)$.

There was a significant correlation between access resistance and age $\left(r_{\mathrm{s}}=-0.41 ; p<0.05\right)$, decreasing in the older animals [14 (13 \pm 7$) \mathrm{M} \Omega ; n=13$ (from 10 animals)] compared with the younger animals [23 (23 \pm 8$) \mathrm{M} \Omega ; n=19$ (from 13 animals)]. Consequently, sEPSC parameters that are sensitive to access resistances would show artifactual developmental changes (Hohnke and Sur, 1996). However, the two parameters that we report on here are relatively insensitive to changes in access resistance. Neither the areas of the SEPSCs $\left(r_{\mathrm{s}}=0.01 ; p>0.05\right)$ nor their IEIs $\left(r_{\mathrm{s}}=-0.17 ; p>0.05\right)$ were correlated with the access resistances. In contrast, peak amplitudes were significantly correlated with access resistance $\left(r_{\mathrm{s}}=-0.42 ; p<0.05\right)$ and remained so when analysis was limited to recordings with access resistances $\leq 20 \mathrm{M} \Omega\left(r_{\mathrm{s}}=-0.71 ; p<0.05\right)$. Whole-cell capacitance was also significantly correlated with age $\left(r_{\mathrm{s}}=0.48 ; p<\right.$ $0.05)$, increasing from a median value of $60(61 \pm 22) \mathrm{pF}$ in the younger animals to $77(76 \pm 22) \mathrm{pF}$ in the older animals. The increase is likely attributable to the developmental increase in soma size during this period (Sutton and Brunso-Bechtold, 1991; Rocha and Sur, 1995). 
A.

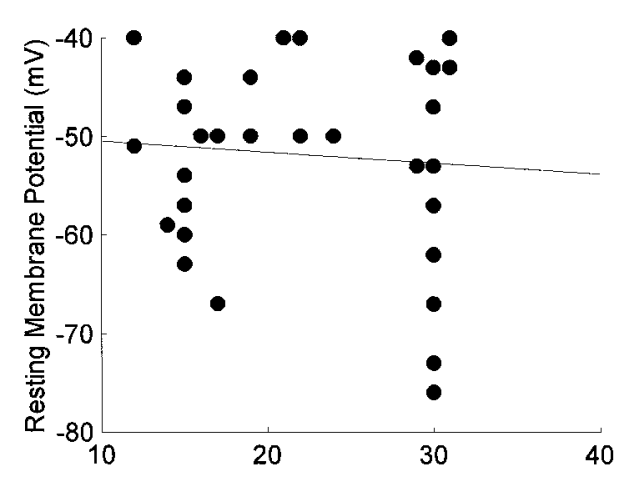

C.

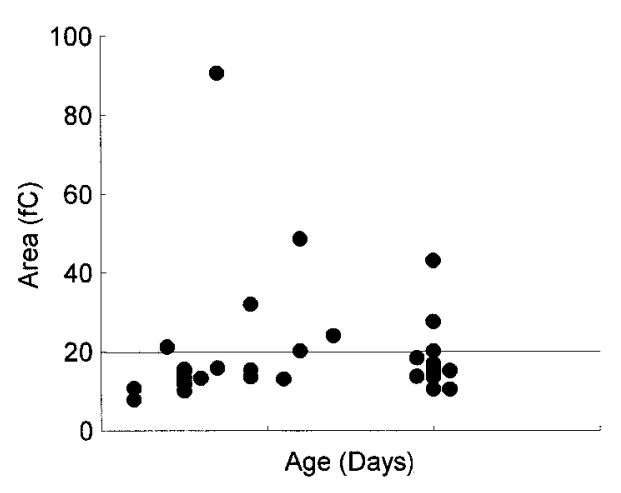

B.

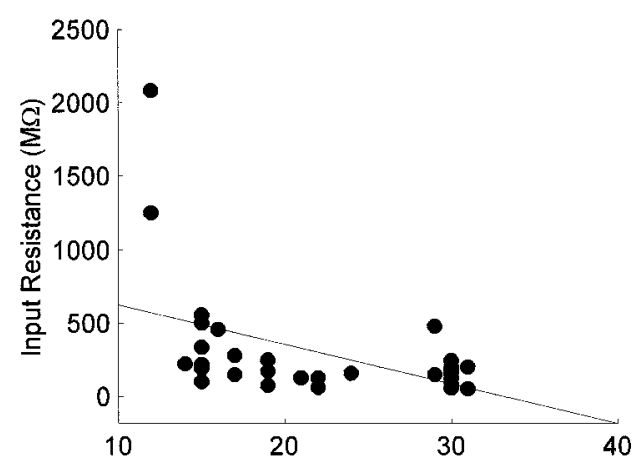

D.

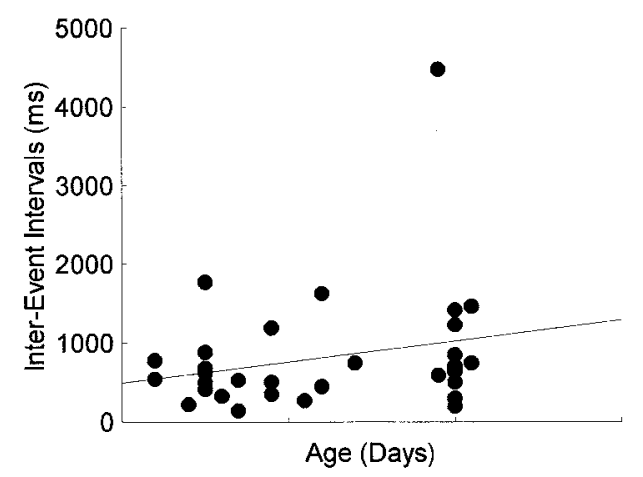

Figure 3. Development of electrophysiological and SEPSC properties of LGN cells during ON/OFF sublamination. Resting membrane potentials of cells were unchanged $(A)$, whereas input resistances decreased significantly $(B)$. The large input resistances recorded at P12 did not alter the significance of the developmental decrease (see Results for details). Neither sEPSC areas $(C)$ nor IEIs $(D)$ changed during this developmental period.

Table 1. Properties of sEPSCs in the LGN during and after ON/OFF sublamination

\begin{tabular}{|c|c|c|c|c|c|c|}
\hline & $n$ & Rise (msec) & Width (msec) & Decay (msec) & Area (fC) & IEI (msec) \\
\hline Younger group & 6 & $0.54(0.57 \pm 0.14)$ & $2.2(2.5 \pm 0.85)$ & $2.1(2.4 \pm 0.82)$ & $14.5(15.1 \pm 2.8)$ & $576(571 \pm 211)$ \\
\hline Older group & 11 & $0.54(0.63 \pm 0.18)$ & $2.7(2.9 \pm 0.83)$ & $2.7(2.8 \pm 0.94)$ & $15(19 \pm 9.4)$ & $744(1181 \pm 1153)$ \\
\hline
\end{tabular}

Access resistance, $\leq 20 \mathrm{M} \Omega$. Parameters calculated as described in Materials and Methods.

There was no correlation between age and resting potential $\left(r_{\mathrm{s}}\right.$ $=0.09 ; p>0.05$; Fig. $3 A)$. Median resting membrane potential was $-50 \mathrm{mV}(-51 \pm 8 \mathrm{mV} ; n=19)$ in younger animals and -53 $\mathrm{mV}(-54 \pm 12 \mathrm{mV} ; n=13)$ in older animals. Input resistances, however, were significantly correlated with age $\left(r_{\mathrm{s}}=-0.53 ; p<\right.$ $0.05)$. Input resistances were quite variable in the younger animals [217 (384 \pm 493$) \mathrm{M} \Omega$ ] and decreased by $33 \%$ in the older animals [147 (166 \pm 109$) \mathrm{M} \Omega$; Fig. 3B]. The variability in input resistances has been noted in other reports of adult and developing LGN cells (Bloomfield et al., 1987; White and Sur, 1992; Ramoa and McCormick, 1994a) and is likely attributable to a large variability in the specific membrane resistance of specific cell types (Bloomfield et al., 1987). Part of the decrease in input resistance was attributable to the large input resistances of the two youngest neurons (P12); nonetheless, excluding these two neurons from the analysis did not change the significance of the correlation $\left(r_{\mathrm{s}}=-0.43 ; p<0.05\right)$.

There was no significant change in the charge transfer of sEPSCs during the period of ON/OFF sublamination (Fig. 3C). Specifically, median area in the younger animals was $15(21 \pm 19)$ $\mathrm{fC}$, and median area in the older animals was $15(18 \pm 9) \mathrm{fC}(p>$ $0.05)$. Neither was the frequency of sEPSCs significantly changed after reorganization of the retinal axons (Fig. 3D). The median IEI in the younger animals [529 $(647 \pm 439) \mathrm{msec}]$ was slightly shorter than in the older animals $[705(1059 \pm 1096)$ msec; $p>$ 0.05]. Limiting the analysis to those recordings with $\leq 20 \mathrm{M} \Omega$ access resistance $(n=17)$ demonstrated that there was no correlation between access resistance and rise times $\left(r_{\mathrm{s}}=0.07 ; p>\right.$ $0.05)$, half-widths $\left(r_{\mathrm{s}}=0.12 ; p>0.05\right)$, and decay times $\left(r_{\mathrm{s}}=0.13\right.$; $p>0.05)$. In this subpopulation of recordings no correlation was observed between age and rise times $\left(r_{\mathrm{s}}=0.27 ; p>0.05\right)$, half-widths $\left(r_{\mathrm{s}}=0.45 ; p>0.05\right)$, or decay times $\left(r_{\mathrm{s}}=0.45 ; p>\right.$ $0.05)$. Both areas and IEIs remained uncorrelated with access resistance and age. Thus, the younger and older groups had equivalent sEPSCs (Table 1).

The sEPSCs we report on in this study were recorded in a number of different conditions that had little effect on their areas or IEIs. To fully characterize sEPSCs in the ferret LGN, we were interested in recording SEPSCs in the presence of an alternate divalent cation. We tested whether replacing calcium with strontium, the most effective substitute for calcium with regard to transmitter release (Miledi 1966; Goda and Stevens, 1994; AbdulGhani et al., 1996; Oliet et al., 1996; Choi and Lovinger, 1997; Morishita and Alger, 1997), would affect the size or frequency of sEPSCs. Our experiments show that strontium is equivalent to calcium in supporting sEPSCs in the developing LGN; both the sEPSC areas and IEIs were unchanged in the presence of strontium (Fig. 4). Recordings in $0 \mathrm{~mm}$ calcium and 1-3 mM strontium 
A. Calcium
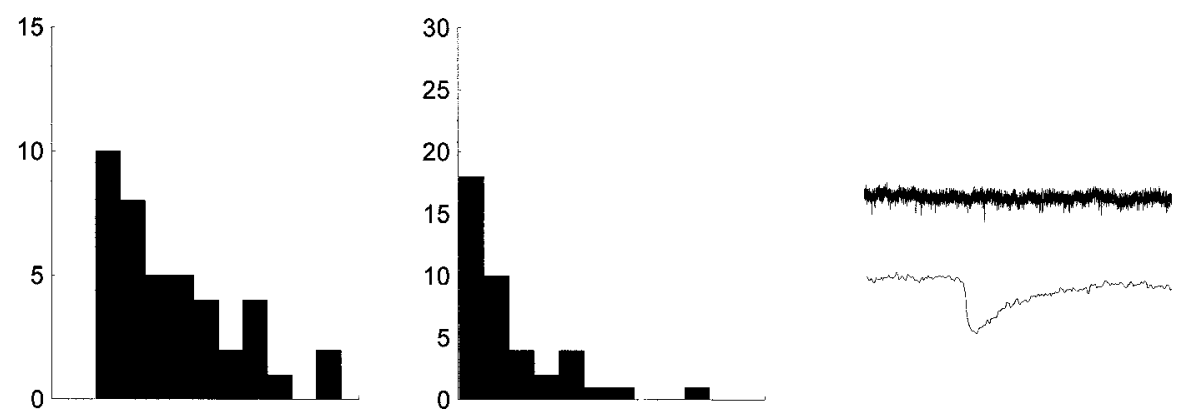

Figure 4. Strontium supports spontaneous synaptic transmission in the developing LGN. Sample histograms of sEPSC areas and IEIs for a P19 neuron recorded in calcium $(A)$ are similar to those for a $\mathrm{P} 15$ neuron recorded in strontium $(B)$. Traces are averages of 25 sEPSCs from each neuron. Strontium was as effective in mediating sEP$\mathrm{SCs}$ as calcium in both the younger and older groups.
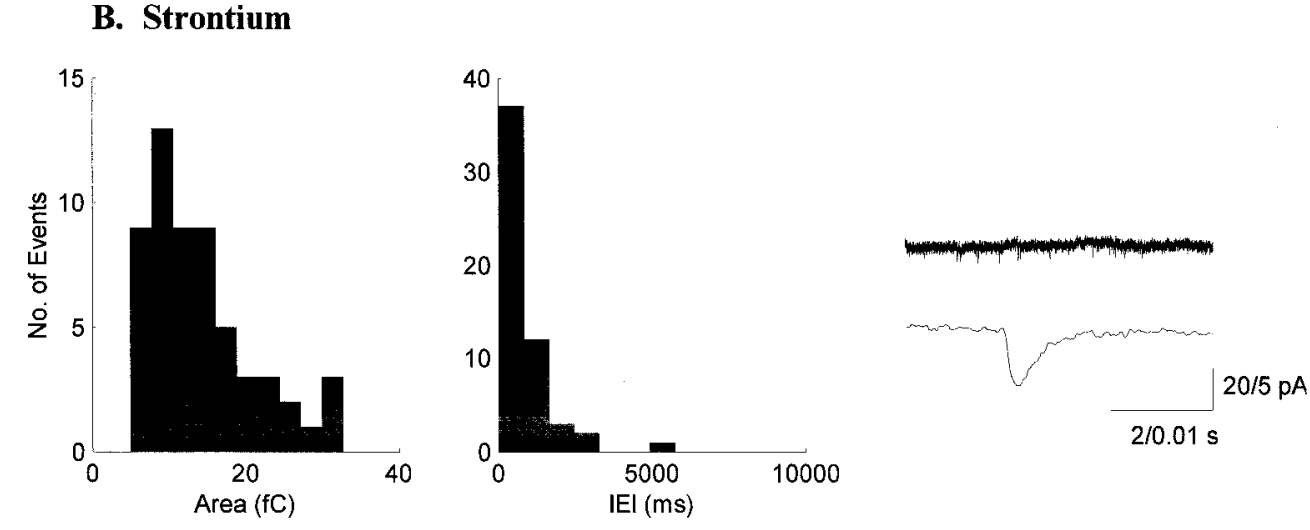

Table 2. Size and frequency of sEPSCs in the LGN under different recording conditions

\begin{tabular}{|c|c|c|c|c|c|c|c|c|c|c|}
\hline & \multicolumn{5}{|c|}{ Younger } & \multicolumn{5}{|c|}{ Older } \\
\hline & \multirow[b]{2}{*}{$n$} & \multicolumn{2}{|c|}{ Area (fC) } & \multicolumn{2}{|c|}{$\begin{array}{l}\text { Interevent interval } \\
(\mathrm{msec})\end{array}$} & \multirow[b]{2}{*}{$n$} & \multicolumn{2}{|c|}{ Area (fC) } & \multicolumn{2}{|c|}{ Interevent interval (msec) } \\
\hline & & Median & $\begin{array}{l}\text { Mean } \pm \\
\text { SD }\end{array}$ & Median & $\begin{array}{l}\text { Mean } \pm \\
\text { SD }\end{array}$ & & Median & $\begin{array}{l}\text { Mean } \pm \\
\text { SD }\end{array}$ & Median & Mean $\pm \mathrm{SD}$ \\
\hline All & 19 & 15.0 & $21.3 \pm 19.2$ & 529 & $647 \pm 439$ & 13 & 15.1 & $18.1 \pm 8.7$ & 705 & $1059 \pm 1096$ \\
\hline $\mathrm{Sr}^{2+} \mathrm{ACSF}$ & 2 & 13.5 & $13.5 \pm 2.7$ & 583 & $583 \pm 126$ & 4 & 18.1 & $23.4 \pm 13.4$ & 932 & $946 \pm 444$ \\
\hline BMI & 13 & 13.5 & $14.7 \pm 6.1$ & 540 & $657 \pm 414$ & 8 & 16.5 & $18.8 \pm 10.4$ & 655 & $1117 \pm 1405$ \\
\hline Cs gluconate & 5 & 10.6 & $11.0 \pm 2.4$ & 540 & $536 \pm 176$ & 3 & 13.6 & $13.7 \pm 3.3$ & 744 & $595 \pm 355$ \\
\hline $34^{\circ} \mathrm{C}$ & 7 & 15.3 & $28.6 \pm 28.2$ & 500 & $692 \pm 590$ & 7 & 15.1 & $20.8 \pm 13.1$ & 672 & $829 \pm 515$ \\
\hline
\end{tabular}

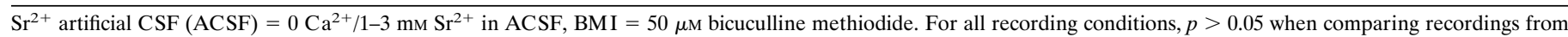
younger and older animals. Access resistance, $\leq 33 \mathrm{M} \Omega$.

revealed sEPSCs with areas [16 $(20 \pm 12) \mathrm{fC}]$ and IEIs [655 $(825 \pm 396) \mathrm{msec} ; n=6]$ that were not different from those recorded in normal calcium $[15(20 \pm 17) \mathrm{fC} ; p>0.05 ; 607$ (812 \pm 859) $\mathrm{msec} ; p>0.05 ; n=26]$. No developmental change in the efficacy of strontium was observed. In strontium solutions, the areas [13.5 $(13.5 \pm 2.7) \mathrm{fC}]$ and IEIs [583 (583 \pm 126$) \mathrm{msec}]$ in the younger group $(n=2)$ were not significantly different from the areas [18.1 (23.4 \pm 13.4$) \mathrm{fC} ; Q=1.23 ; p>0.05$, Kruskal-Wallis nonparametric ANOVA] and IEIs [932 (946 \pm 444$)$ msec; $Q=$ $0.86 ; p>0.05$ ] in the older group $(n=4$; Table 2$)$.

The vast majority of sEPSCs that we recorded were CNQXsensitive, quantal events: CNQX $(10 \mu \mathrm{M})$ blocked all sEPSCs $(n=3$; Fig. $5 A)$, and sEPSCs under TTX blockade were similar to normal sEPSCs (Fig. 5B). The distributions of the IEIs in control $[759(668 \pm 249) \mathrm{msec}]$ and TTX [483 (612 \pm 358$) \mathrm{msec}]$ solutions were not significantly different (in all cases $p>0.05$, Kolmogorov-Smirnov test; $n=4$; Fig. $5 C$ ). Likewise, there was no significant change in sEPSC areas in TTX $[13(13 \pm 5) \mathrm{fC}]$ compared with control $[13(13 \pm 2) \mathrm{fC}]$ solutions (in one case $p=$ 0.02; in three cases $p>0.05$, Kolmogorov-Smirnov test; Fig. 5D). By clamping the cells at $-60 \mathrm{mV}$, close to the chloride reversal potential, we expected to not detect any spontaneous inhibitory postsynaptic currents. Indeed, no significant differences in areas or IEIs were observed between control $(n=7)$ and BMI solutions $(n=21)$ when recording from animals of similar ages (Table 2$)$.

Additionally, eight recordings with cesium gluconate in the recording electrode produced sEPSCs similar to those recorded with potassium gluconate $(n=24)$. A slight but significant difference was observed between sEPSC areas recorded from younger animals with cesium gluconate and sEPSC areas recorded from older animals with potassium gluconate $(Q=2.75 ; 0.02<p<$ $0.05)$. However, no significant differences in areas or IEIs were observed between the intracellular solutions when recording from animals of similar ages. There were also no significant differences 
B.

A.

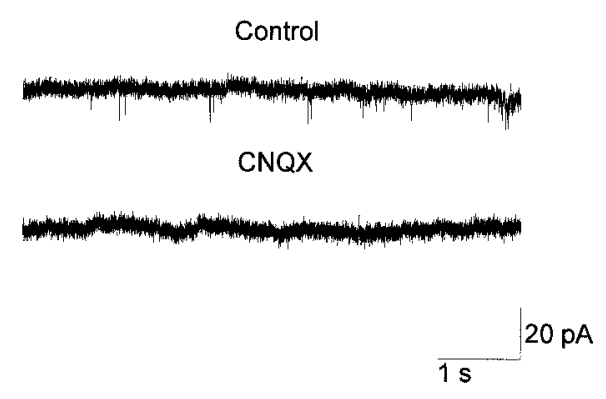

C.

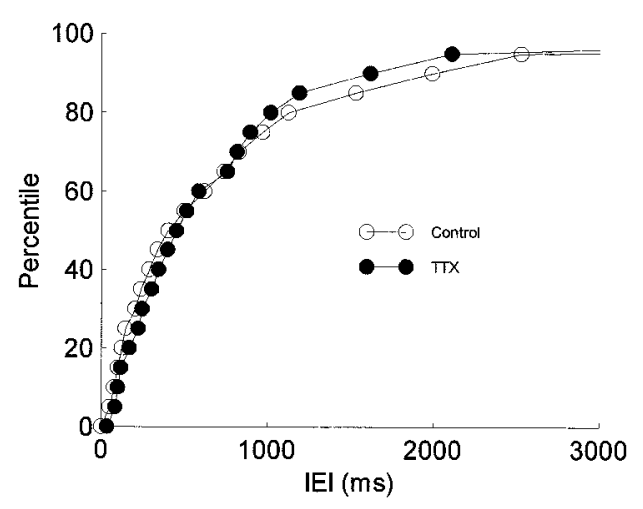

Control

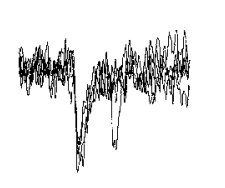

TTX
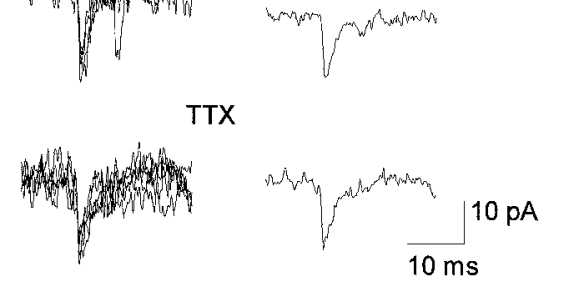

D.

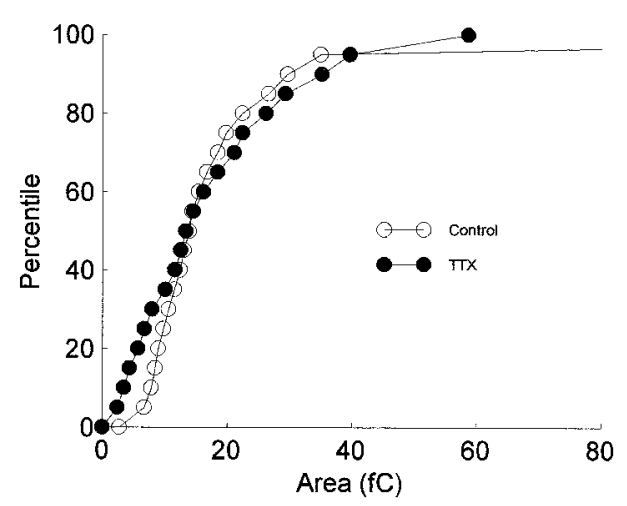

Figure 5. sEPSCs at resting membrane potential are AMPA-mediated, quantal events. $A, \mathrm{CNQX}$ blocked all sEPSCs. $B$, Five individual sEPSCs and their average traces are shown for control and TTX conditions. Cumulative amplitudes of sEPSC IEIs $(C)$ and areas $(D)$ show no difference between sEPSCs recorded in control and TTX solutions. The sEPSCs from four experiments are combined in each condition for illustrative purposes. Statistical analyses were performed for each experiment individually (see Materials and Methods for details).

in areas or IEIs between sEPSCs recorded at room temperature and those recorded at $34^{\circ} \mathrm{C}(p>0.05$; Table 2$)$.

Finally, we examined the coefficient of variation $(\mathrm{CV})$ of the areas and IEIs of the sEPSCs to determine whether changes in the variability of these parameters occurred during ON/OFF sublamination. There was no age-dependent change in the variability of sEPSCs within a recording for any of the parameters measured. The median CV (of the individual CVs) for area was 0.58 in the younger animals and 0.57 in the older animals. The median CV for IEI was 1.1 in both the younger and older animals. There was also no change in the variability of sEPSCs between recordings. The variance of the median values in the younger group was not different from the variance in the older group for all the parameters measured ( $p>0.5$, Siegel-Tukey test).

\section{Evoked miniature EPSCs}

To examine the retinal synapses specifically, we evoked asynchronous transmitter release by stimulating the optic tract after replacing extracellular calcium with strontium (Miledi, 1966; Goda and Stevens, 1994; Abdul-Ghani et al., 1996; Oliet et al., 1996; Choi and Lovinger., 1997; Morishita and Alger, 1997). Replacing extracellular calcium with strontium caused a marked decrease in the normal, synchronous release of transmitter and caused an afterdischarge of miniature EPSCs lasting up to $1 \mathrm{sec}$ but occurring primarily in the first $500 \mathrm{msec}$ (Fig. 6).

Evoked miniature EPSCs were analyzed in 11 additional cells from animals between P15 and P31. We recorded 762 emEPSCs from younger animals and 529 emEPSCs from older animals. Typical distributions of areas and the averaged emEPSC for one younger cell and one older cell are shown in Figure 7. As with sEPSCs, histograms of emEPSC parameters showed skewed distributions at all ages. More specifically, pooled data from the youngest $(n=5)$ and the oldest $(n=5)$ cells show emEPSC area histograms with similar shapes (Fig. $8 A$ ). The cumulative histograms were the same for the two groups ( $p>0.05$, KolmogorovSmirnov test; Fig. $8 B$ ), as were the distributions for rise, width, and decay times $(p>0.05)$.

The access resistances of the recordings in this set of experiments were $<20 \mathrm{M} \Omega$. The areas $\left(r_{\mathrm{s}}=0.22 ; p>0.05\right)$, rise times $\left(r_{\mathrm{s}}=0.08 ; p>0.05\right)$, and decay times $\left(r_{\mathrm{s}}=0.05 ; p>0.05\right)$ of the emEPSCs were not correlated with access resistance. The peak amplitudes of the emEPSCs, however, tended to correlate with the access resistance $\left(r_{\mathrm{s}}=-0.54 ; p=0.06\right)$ as they did for the recordings of sEPSCs.

The input resistances of the recordings in this set of experiments revealed the same developmental decrease that was observed during the first set of experiments. Input resistance in the younger animals was $455(424 \pm 116) \mathrm{M} \Omega$, and input resistance in the older animals was $116(191 \pm 193) \mathrm{M} \Omega\left(r_{\mathrm{s}}=-0.58 ; p<0.05\right)$.

The properties of emEPSCs recorded from younger animals $[n=5$ (from three animals) $]$ before ON/OFF sublamination were not different from those made from older animals $[n=6$ (from four animals)] after sublamination was complete. Median area in the younger animals was $16(14 \pm 4) \mathrm{fC}$, and median area in the older animals was $22(23 \pm 11) \mathrm{fC}(p>0.05$; Table 3$)$. Rise times, widths, and decay times were also unchanged after the completion of sublamination ( $p>0.05$ for all comparisons; Table 3 ). No correlation was observed between age and emEPSC rise times $\left(r_{\mathrm{s}}\right.$ $=0.31 ; p>0.05)$, areas $\left(r_{\mathrm{s}}=0.29 ; p>0.05\right)$, half-widths $\left(r_{\mathrm{s}}=\right.$ $0.36 ; p>0.05)$, or decay times $\left(r_{\mathrm{s}}=0.41 ; p>0.05\right)$.

In general, emEPSCs and sEPSCs were quite similar. emEPSC areas in the younger animals [16 $(14 \pm 4) \mathrm{fC}]$ were not different from sEPSCs in the younger animals [15 (21 \pm 19$) \mathrm{fC} ; p>0.05]$, 
A.

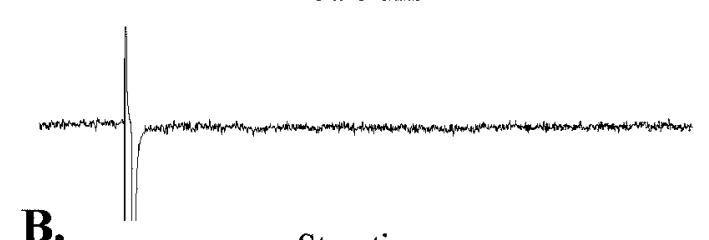

B.

Strontium

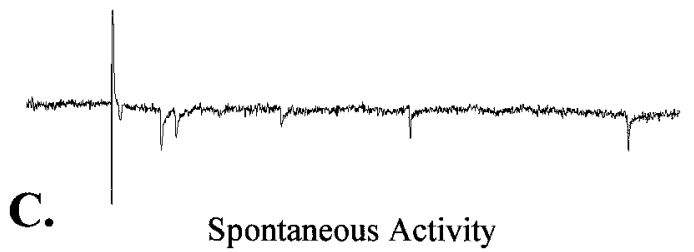

Spontaneous Activity
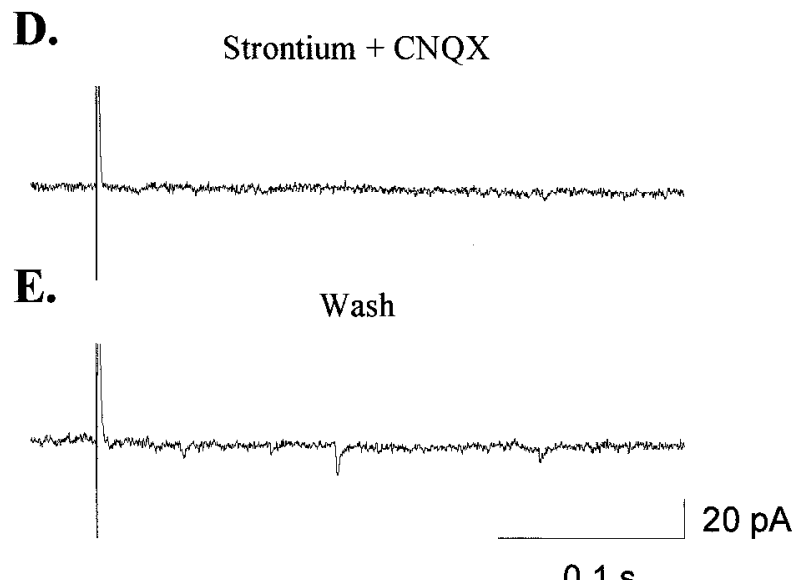

$0.1 \mathrm{~s}$

Figure 6. Replacing extracellular calcium with strontium allows for the analysis of unitary, retinal EPSCs. $A$, Stimulation of the optic tract in the presence of normal calcium results in a large EPSC. $B$, Replacing calcium with strontium causes a marked decrease in the synchronous response to stimulation and generates a discharge of asynchronous transmitter release. $C$, In the absence of stimulation, the frequency of sEPSCs is extremely low, suggesting that there is little contamination of the emEPSCs by sEPSCs of unknown origin. $D$, CNQX blocked all emEPSCs as well as what remains of the synchronous response in strontium. $E$, Responses to stimulation recovered after removal of CNQX from the bath.

nor were emEPSCs in the older animals [23 (23 \pm 11$)$ fC] different from sEPSCs in the older animals [15 (18 \pm 9$) \mathrm{fC} ; p>$ 0.05]. Rise times, widths, and decay times of emEPSCs were not different from those calculated for sEPSCs (compare Tables 1 and 3). More specifically, the areas and decay times of emEPSCs and sEPSCs from the same recordings were not different from one another $(n=2$; in both cases $p>0.05$, Kolmogorov-Smirnov test). In one cell, the rise times of the emEPSCs [0.41 (0.44 \pm $0.15) \mathrm{msec}]$ were slightly shorter than those of the sEPSCs [0.48 $(0.54 \pm 0.19)$ msec; $p<0.05$, Kolmogorov-Smirnov test] from the same recording. emEPSCs, like sEPSCs, were AMPA-mediated at resting membrane potentials and could be blocked completely with CNQX (10 $\mu \mathrm{M} ; n=6$; Fig. 6). Last, the within-cell CV showed no age-dependent change for any of the parameters measured, nor was there a change in the variability of sEPSCs between recordings $(p>0.05$, Siegel-Tukey test).

\section{DISCUSSION}

We have demonstrated that sEPSCs are present in ferret LGN cells as early as P12 and occur throughout the period of ON/OFF sublamination. The results presented here suggest that the basic physiological properties of these unitary inputs onto LGN cells are present at the beginning of ON/OFF sublamination and do not change significantly, although at least the retinal inputs are undergoing dramatic, activity-dependent anatomical reorganization and development. Because the population of sEPSCs recorded from a neuron may be generated from a heterogeneous set of synapse types (e.g., retinal and cortical synapses), it is possible that changes occurring among one of those types are masked in our data. We examined retinal synapses specifically and show that unitary, AMPA-mediated, retinal EPSCs remain unchanged during ON/OFF sublamination and are not different from the population of sEPSCs. Indeed, the similarity of sEPSCs and emEPSCs suggests that sEPSCs might derive largely if not solely from retinal synapses.

We analyzed these data for group differences (younger vs older group) as well as for correlation with age. Sublaminae can first be seen by P21 (Hahm et al., 1991) and are sharply segregated by P26 (Cramer et al., 1996). There were very few cells in our sample between P21 and P24 (see Fig. 3); their properties were not different from the younger group of cells, and they were included in this group for analysis. Furthermore, the correlation analyses showed no trend in any of the EPSC parameters with age.

Three caveats to our data should be noted. First, we recorded from a heterogeneous population of cells in the A layers of the LGN that include X-cells, Y-cells, and interneurons. It is unlikely that we recorded from many interneurons: recordings from cells with small somas [which are characteristic of interneurons (Friedlander et al., 1981)] were avoided, and all cells included in the analysis displayed easily evoked low-threshold calcium spikes, a characteristic of LGN relay cells (McCormick and Pape, 1988). However, although we observed no systematic variations in our data that might correlate with different LGN cell types, such a relationship cannot be excluded. Second, we recorded EPSCs only at resting membrane potentials. Hence, changes at synapses mediated by conductances not active at rest (NMDA receptors, for example) cannot be excluded. Third, to the extent that changes in presynaptic transmitter release are not well assayed by the frequency of sEPSCs (see below), they would not have been detected by these experiments.

Another issue deserves comment. It is possible that immature inputs may have such low sEPSC amplitudes and/or frequencies that they cannot be reliably detected. However, our detection thresholds allowed us to detect sEPSCs with extremely small amplitudes and areas (e.g., we detected events with amplitudes that were less than two times the SD of the baseline noise). Additionally, we observed no increase in sEPSC frequency, which would be expected if undetectably low, immature sEPSC frequencies matured to the frequencies we observed during ON/OFF sublamination.

\section{Comparison with other systems}

The lack of developmental changes in sEPSCs that we observe in the LGN are similar to those reported for unitary EPSCs in the rat neocortex (Burgard and Hablitz, 1993). That is, the characteristics of sEPSCs are present early in development and do not change significantly during the third and fourth postnatal weeks. The development of sEPSCs, miniature EPSCs (mEPSCs), and minimal evoked EPSPs (meEPSPs) have also been examined in 
A. P15

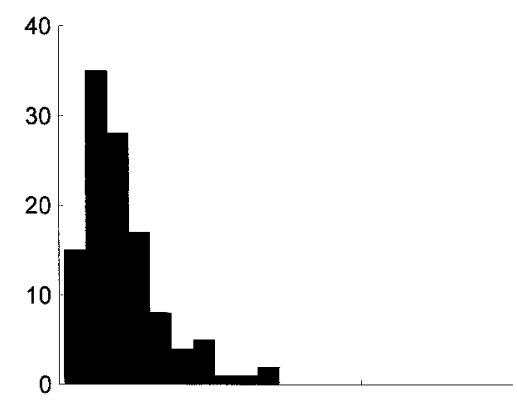

B. P31

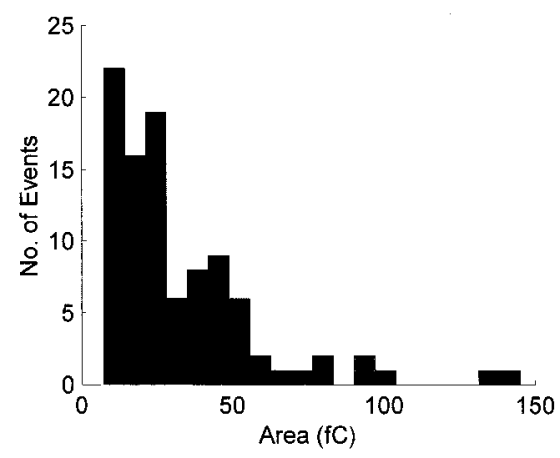

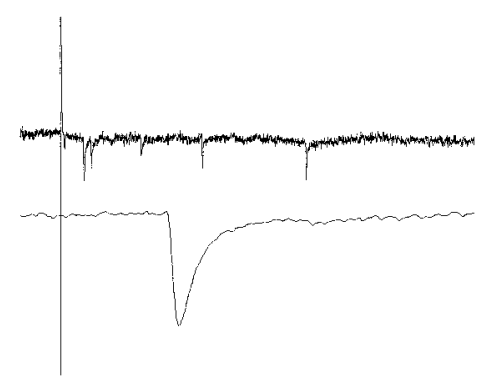

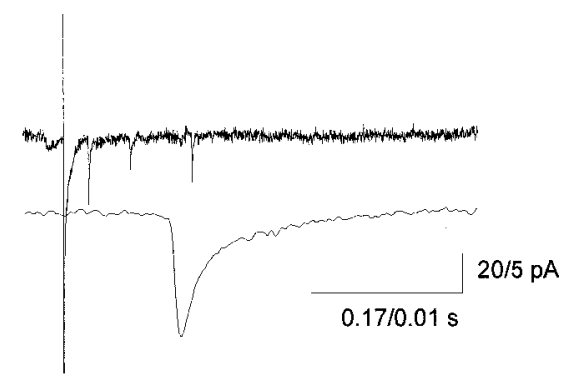

Figure 7. emEPSC areas in the LGN are stable during ON/OFF sublamination. Histograms of emEPSC areas and example current traces from a $\mathrm{P} 15(A)$ and a $\mathrm{P} 31(B)$ neuron are shown. The bottom traces for each neuron are averages of 50 consecutive emEPSCs. other systems. The amplitude of sEPSCs and mEPSCs does not change in early development in the rat superior colliculus and visual cortex (Carmignoto and Vicini, 1992; Hestrin, 1992; Shi et al., 1997). A developmental increase in meEPSP amplitudes between the third and fifth postnatal weeks has been reported in the rat hippocampus to be attributable to an increase in quantal content as opposed to quantal size (Dumas and Foster, 1995). In fact, as in our study, mEPSCs do not increase in size during hippocampal development (Hsia et al., 1998). In the rat superior colliculus, NMDA-mediated mEPSC and sEPSC decay times decrease during the second and third postnatal weeks (Hestrin, 1992; Shi et al., 1997); NMDA-mediated decay times also decrease with age in visual cortex (Carmignoto and Vicini, 1992). The differences observed in the development of mEPSCs in various mammalian brain regions may be attributable to intrinsic differences in those regions or differences in the recording conditions. For example, the experiments in visual cortex and superior colliculus were concerned with isolating the NMDA components of the mEPSCs and recorded events in the presence of zero magnesium and/or at extremely depolarized potentials. In addition, Hestrin (1992) reported a qualitative, but not a quantitative, decline in mEPSC decay time in the superior colliculus. Shi et al. (1997) reported a decrease in sEPSC frequency after retinocollicular map refinement in the rat that they suggest may be attributable to the onset of $\mathrm{GABA}_{\mathrm{A}}$-mediated inhibition. $\mathrm{GABA}_{\mathrm{A}}$ - and $\mathrm{GABA}_{\mathrm{B}}$-mediated inhibition first appear in the developing ferret LGN at P15 and between P21 and P30, respectively (Ramoa and McCormick, 1994b), but we observed no significant decrease in the frequency of sEPSCs at those times. In contrast, mEPSC frequency has been reported to increase dramatically during hippocampal development (Hsia et al., 1998). In any case, a change in unitary EPSC frequency would be difficult to interpret in developmental slice physiology studies. Changes in frequency could be attributable to the slightly different planes of section
(Staley and Mody, 1991) and/or changes in the number of preserved contacts in a slice resulting from the growth and movement of a structure during development. Last, Blanton and Kriegstein (1991) reported increases in frequency and rise and decay times of mEPSCs during embryonic development of the turtle cortex. These changes contrast with what is observed in the rat and ferret and may be attributable to species differences or a difference in the developmental stage between an embryonic turtle cortex and postnatal cortical and subcortical structures in mammals.

\section{Retinogeniculate transmission during sublaminar segregation}

We show that strontium can substitute for calcium in mediating sEPSCs at retinogeniculate synapses. No change in sEPSC size or frequency is observed when calcium is replaced with equal concentrations of strontium. Strontium has been shown to be the most efficient substitute for calcium at the neuromuscular junction (Miledi, 1966; Dodge et al., 1969; Meiri and Rahamimoff, 1971; Bain and Quastel, 1992). Fast synchronous release is inhibited when calcium is replaced with strontium, but the slower, asynchronous release is facilitated. Transmitter release is quantal in strontium, and spontaneous release continues. Similar findings have been reported more recently in the CNS (Goda and Stevens, 1994; Abdul-Ghani et al., 1996; Oliet et al., 1996; Choi and Lovinger, 1997; Morishita and Alger, 1997). In hippocampal slices, as in our study, the size and frequency of sEPSCs are unchanged in the presence of strontium (Oliet et al., 1996). In addition to showing that strontium can be substituted for calcium, our findings show that the efficacy of that substitution is not altered during a period of activity-dependent plasticity in early development.

We observe stable resting membrane potentials (RMPs) and a decrease in input resistances of LGN cells during sublamination. 

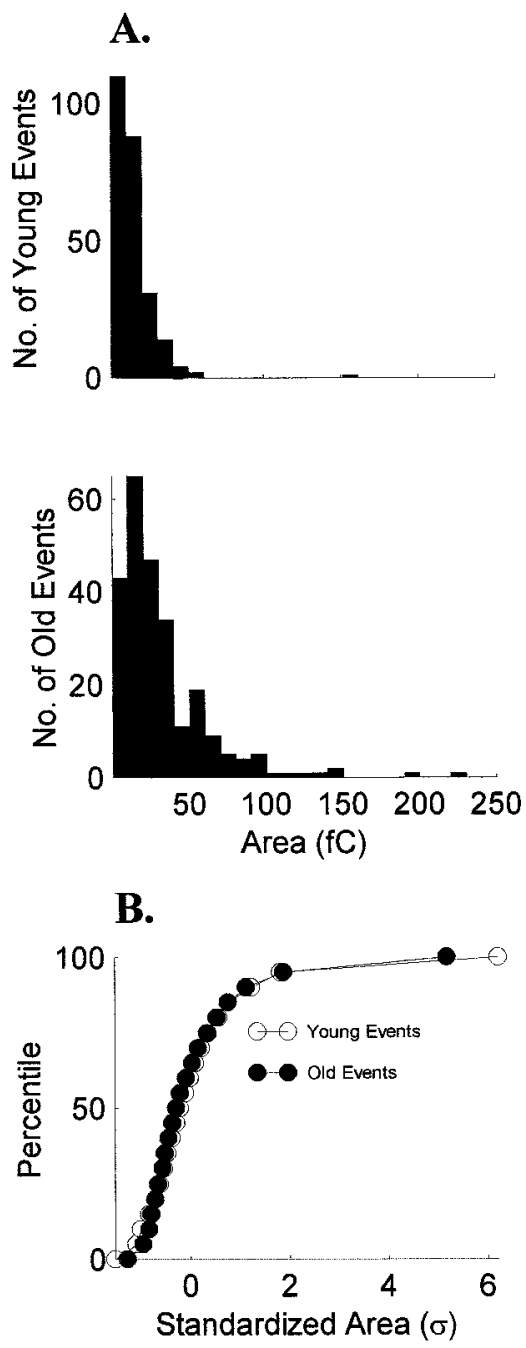

Figure 8. The shape of emEPSC area distributions is stable over ON/ OFF sublamination. $A$, Histograms of pooled data from the youngest cells $(n=5)$ and the oldest cells $(n=5)$ are similar for sEPSC area. $B$, Cumulative histograms of the standardized areas show that the shapes of the distributions did not change with age $(p>0.05$, KolmogorovSmirnov test).

Two previous reports of the physiological development of ferret LGN cells, one using intracellular recordings (White and Sur, 1992) and the other using whole-cell patch-clamp (Ramoa and McCormick, 1994a), likewise reported a developmental decrease in input resistance and stable RMPs during the third and fourth postnatal weeks. A developmental decrease in input resistance has also been reported in mouse thalamus (Warren and Jones, 1997), rat thalamus (Perez Velazquez and Carlen, 1996), rat superior olivary complex (Kandler and Friauf, 1995), rat hippocampus (Spigelman et al., 1992), and rat neocortex (McCormick and Prince, 1987; Annis et al., 1993). In the LGN, it is possible that the observed developmental decrease in input resistance reflects a bias toward recording from Y-cells toward the end of sublamination. Y-cells have larger somata and lower input resistances than X-cells in the adult cat (Crunelli et al., 1987) and response properties that develop later than those of X-cells (Daniels et al., 1978). It is also possible that the decrease in input resistance reflects the developmental increase in soma size of both X- and Y-cells (Rocha and Sur, 1995).

The developmental changes in receptor subunit composition and the putative role for LTP during development (see introductory remarks) suggest a change in spontaneous and evoked miniature EPSCs during ON/OFF sublamination of synapses mediated by NMDA and AMPA receptors on LGN cells. What might account for the stability of synaptic efficacy during a period of dramatic reorganization of afferents and pattern formation?

It is possible that homeostatic mechanisms maintain a constant synaptic efficacy during the period of ON/OFF sublamination. Such homeostasis may be of two types. First, it has been shown that quantal amplitudes in cultured neocortical pyramidal neurons are globally modulated by activity (Turrigiano et al., 1998), so that blockade of activity results in a scaling up of sEPSC amplitudes. Similarly, quantal amplitudes in cultured hippocampal neurons are negatively correlated with the number of synaptic contacts on these cells (Liu and Tsien, 1995). On this view, if the number of synaptic contacts (particularly retinal synapses) on LGN cells increases during sublamination, the amplitude (or areas) of sEPSCs and emEPSCs should decrease. The fact that sEPSC and emEPSC areas remain similar through the period of sublamination may be indicative of no major change in the overall number of at least retinal synapses during this period. Indeed, the available data on postnatal cats (Kalil and Scott, 1979) is difficult to relate to postnatal ferrets and can be interpreted as reflecting only a modest increase in retinogeniculate synapses over a period similar to the P14-P28 period in ferrets.

Second, synaptic rearrangement during ON/OFF sublamination implies that some synapses-presumably incorrect ones-are lost or retracted from cells, whereas new synapses are added. One interpretation of the data presented here is that the new synapses have properties very similar to the ones they replace (Fig. 9). It is possible that the postsynaptic cell provides such stability, with synapses targeted to specific dendritic sites regulated to have specific properties. An alternative possibility is that retinogeniculate synapses are correctly targeted in location and number by P14 and sublamination consists of the separation of ON-center and OFF-center axon-cell pairs to the appropriate sublayer by $\mathrm{P} 28$ (Fig. 9).

These results add complexity to the hypothesis that developmental changes in connectivity are mirrored by changes in synaptic efficacy (Constantine-Paton et al., 1990; Kandel and O’Dell, 1992; Goodman and Shatz, 1993; Cramer and Sur, 1995; Katz and Shatz, 1996; Constantine-Paton and Cline, 1998). Although we did not follow individual synapses over time, the population data do not indicate that a subset of synapses is strengthened whereas

$\begin{aligned} & \text { Table 3. Properties of evoked miniature retinal EPSCs in the LGN during and after ON/OFF } \\
& \text { sublamination }\end{aligned}$
\begin{tabular}{llllll} 
& & & & \\
& $n$ & Rise $(\mathrm{msec})$ & Width $(\mathrm{msec})$ & Decay $(\mathrm{msec})$ & Area (fC) \\
\hline Younger group & 5 & $0.37(0.41 \pm 0.08)$ & $2.09(2.17 \pm 0.25)$ & $1.78(1.75 \pm 0.13)$ & $16(14 \pm 4)$ \\
Older group & 6 & $0.56(0.54 \pm 0.17)$ & $3.83(3.89 \pm 1.77)$ & $3.03(2.97 \pm 1.13)$ & $22(23 \pm 11)$ \\
\hline
\end{tabular}



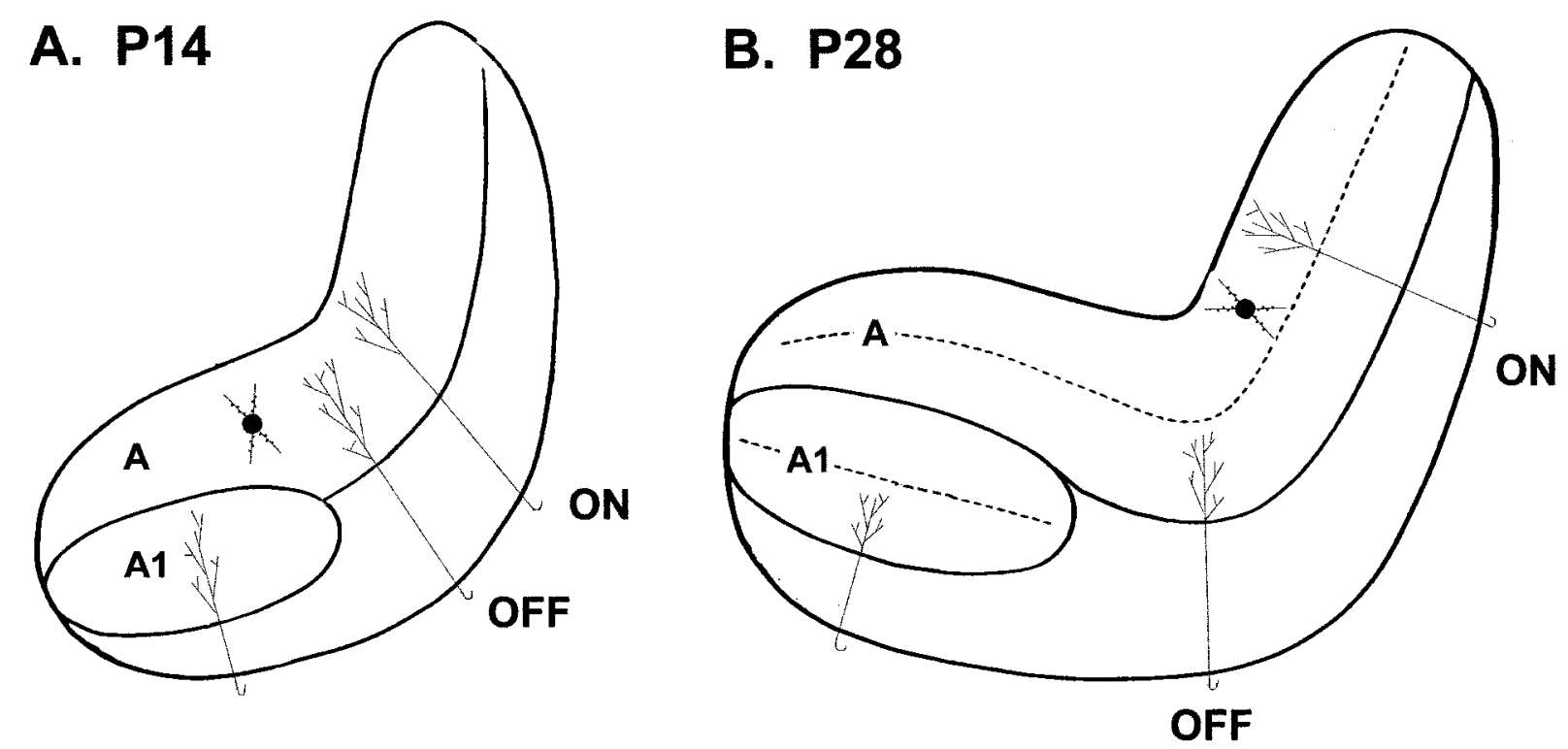

C.

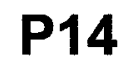

P28
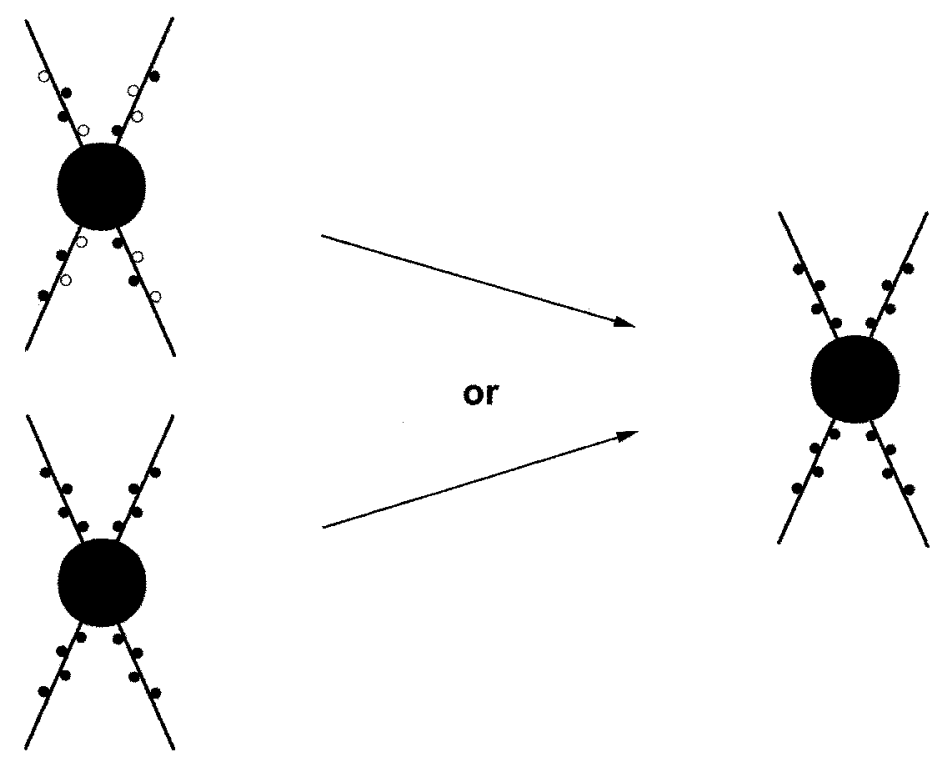

\section{- on center retinogeniculate axon synapse o off center retinogeniculate axon synapse}

Figure 9. Efficacy of AMPA-synapses on LGN cells appears to be normalized such that it remains stable throughout changes in neural activity and connectivity. $A$, Before ON/OFF sublamination retinal axons arborize in "inappropriate" areas of the LGN and may or may not make significant synaptic contacts outside of the areas that they will later be restricted to. $B$, After sublamination is complete, relay cells in the LGN receive inputs exclusively from either ON- or OFF-center retinal axons. $C$, Schematic of two possible explanations for the stability of synaptic efficacy during the activity-dependent reorganization of retinal axons in the LGN. If synaptic efficacy in the LGN is inversely proportional to the number of synaptic contacts as it is in the hippocampus (see Discussion for details), then either inappropriate inputs (open circles) have similar synaptic efficacies and are replaced by an equal number of appropriate inputs (closed circles), or only appropriate inputs are in place before sublamination, and their number does not increase. 
another is weakened and retracted over the period of sublamination. Rather, the results presented here suggest that total synaptic input to a neuron is "normalized" toward some acceptable level and that if LTP is involved in the stabilization of appropriate synapses during development, a subsequent mechanism counteracts its effects. For example, an LTP-like mechanism by which changes in synaptic efficacy decays over a period of hours (Cline, 1991), but which initially mediates synapse stabilization, may exist and would not be detected by these experiments.

\section{REFERENCES}

Abdul-Ghani MA, Valiante TA, Pennefather P (1996) $\mathrm{Sr}^{2+}$ and quantal events at excitatory synapses between mouse hippocampal neurons in culture. J Physiol (Lond) 95:113-125.

Aghajanian GK, Rasmussen K (1989) Intracellular studies in the facial nucleus illustrating a simple new method for obtaining viable motoneurons in adult rat brain slices. Synapse 3:331-338.

Annis CM, Robertson RT, O’Dowd DK (1993) Aspects of early postnatal development of cortical neurons that proceed independently of normally present extrinsic influences. J Neurobiol 24:1460-1480.

Bain AI, Quastel DM (1992) Quantal transmitter release mediated by strontium at the mouse motor nerve terminal. J Physiol (Lond) 450:63-87.

Blanton MG, Kriegstein AR (1991) Spontaneous action potential activity and synaptic currents in the embryonic turtle cerebral cortex. J Neurosci 11:3907-3923.

Blanton MG, LoTurco JJ, Kriegstein AR (1989) Whole cell recording from neurons in slices of reptilian and mammalian cerebral cortex. J Neurosci Methods 30:203-210.

Bliss TV, Collingridge GL (1993) A synaptic model of memory: longterm potentiation in the hippocampus. Nature 361:31-39.

Bloomfield SA, Hamos JE, Sherman SM (1987) Passive cable properties and morphological correlates of neurones in the lateral geniculate nucleus of the cat. J Physiol (Lond) 383:653-692.

Burgard EC, Hablitz JJ (1993) NMDA receptor-mediated components of miniature excitatory synaptic currents in developing rat neocortex. J Neurophysiol 70:1841-1852.

Cabelli RJ, Hohn A, Shatz CJ (1995) Inhibition of ocular dominance column formation by infusion of NT-4/5 or BDNF. Science 267:1662-1666.

Carmignoto G, Vicini S (1992) Activity-dependent decrease in NMDA receptor responses during development of the visual cortex. Science 258:1007-1011.

Choi S, Lovinger DM (1997) Decreased frequency but not amplitude of quantal synaptic responses associated with expression of corticostriatal long-term depression. J Neurosci 17:8613-8620.

Cline HT (1991) Activity-dependent plasticity in the visual systems of frogs and fish. Trends Neurosci 14:104-111.

Colman H, Nabekura J, Lichtman JW (1997) Alterations in synaptic strength preceding axon withdrawal. Science 275:356-361.

Constantine-Paton M, Cline HT (1998) LTP and activity-dependent synaptogenesis: the more alike they are, the more different they become. Curr Opin Neurobiol 8:139-148.

Constantine-Paton M, Cline HT, Debski E (1990) Patterned activity, synaptic convergence, and the NMDA receptor in developing visual pathways. Annu Rev Neurosci 13:129-154.

Cook PM, Prusky G, Ramoa AS (1996) Role of spontaneous retinal activity in reorganization of retinogeniculate connections during development. Soc Neurosci Abstr 22:761.

Cramer K, Sur M (1995) Activity-dependent remodeling of connections in the mammalian visual system. Curr Opin Neurobiol 5:106-111.

Cramer KS, Sur M (1997) Blockade of afferent impulse activity disrupts on/off sublamination in the ferret lateral geniculate nucleus. Dev Brain Res 98:287-290.

Cramer KS, Angelucci A, Hahm JO, Bogdanov MB, Sur M (1996) A role for nitric oxide in the development of the ferret retinogeniculate projection. J Neurosci 16:7995-8004.

Crunelli V, Leresche N, Parnavelas JG (1987) Membrane properties of morphologically identified $\mathrm{X}$ and $\mathrm{Y}$ cells in the lateral geniculate nucleus of the cat in vitro. J Physiol (Lond) 390:243-256.

Dalva MB, Ghosh A, Shatz CJ (1994) Independent control of dendritic and axonal form in the developing lateral geniculate nucleus. J Neurosci 14:3588-3602.
Daniels J, Pettigrew J, Norman J (1978) Development of single-neuron responses in kitten's lateral geniculate nucleus. J Neurophysiol 41:1373-1393.

Dodge Jr FA, Miledi R, Rahamimoff R (1969) Strontium and quantal release of transmitter at the neuromuscular junction. J Physiol (Lond) 200:267-283.

Dumas TC, Foster TC (1995) Developmental increase in CA3-CA1 presynaptic function in the hippocampal slice. J Neurophysiol 73:1821-1828.

Durand GM, Zukin RS (1993) Developmental regulation of mRNAs encoding rat brain kainate/AMPA receptors: a Northern analysis study. J Neurochem 61:2239-2246.

Esguerra M, Kwon YH, Sur M (1992) Retinogeniculate EPSPs recorded intracellularly in the ferret lateral geniculate nucleus in vitro: role of NMDA receptors. Vis Neurosci 8:545-555.

Friedlander MJ, Lin GS, Stanford LR, Sherman SM (1981) Morphology of functionally identified neurons in the lateral geniculate nucleus of the cat. J Neurophysiol 46:80-129.

Goda Y, Stevens CF (1994) Two components of transmitter release at a central synapse. Proc Natl Acad Sci USA 91:12942-12946.

Goodman CS, Shatz CJ (1993) Developmental mechanisms that generate precise patterns of neuronal connectivity. Cell 72:77-98.

Hahm J-O, Langdon RB, Sur M (1991) Disruption of retinogeniculate afferent segregation by antagonists to NMDA receptors. Nature 3551:568-570.

Hestrin S (1992) Developmental regulation of NMDA receptormediated synaptic currents at a central synapse. Science 357:686-689.

Hestrin S (1993) Different glutamate receptor channels mediate fast excitatory synaptic currents in inhibitory and excitatory cortical neurons. Neuron 11:1083-1091.

Hofer M, Prusky GT, Constantine-Paton M (1994) Regulation of NMDA receptor mRNA during visual map formation and after receptor blockade. J Neurochem 62:2300-2307.

Hohnke C, Sur M (1996) Developmental changes in spontaneous EPSCs during $\mathrm{ON} / \mathrm{OFF}$ sublamination in the ferret lateral geniculate nucleus. Soc Neurosci Abstr 22:760.

Hohnke C, Sur M (1998) Stable properties of spontaneous EPSCs and miniature retinal EPSCs during the development of ON/OFF sublamination in the ferret lateral geniculate nucleus. Soc Neurosci Abstr 24:811.

Hsia AY, Malenka RC, Nicoll RA (1998) Development of excitatory circuitry in the hippocampus. J Neurophysiol 79:2013-2024.

Jakowec MW, Yen L, Kalb RG (1995) In situ hybridization analysis of AMPA receptor subunit gene expression in the developing rat spinal cord. Neuroscience 67:909-920.

Jonas P, Major G, Sakmann B (1993) Quantal components of unitary EPSCs at the mossy fibre synapse on CA3 pyramidal cells of the rat hippocampus. J Physiol (Lond) 427:615-663.

Kalil RE, Scott G (1979) Development of retinogeniculate synapses in the dorsal lateral geniculate nucleus of the cat. Soc Neurosci Abstr 5:91.

Kalil RE, Dubin MW, Scott G, Stark LA (1986) Elimination of action potentials blocks the structural development of retinogeniculate synapses. Nature 323:156-158.

Kandel ER, O’Dell TJ (1992) Are adult learning mechanisms also used for development? Science 258:243-245.

Kandler K, Friauf E (1995) Development of electrical membrane properties and discharge characteristics of superior olivary complex neurons in fetal and postnatal rats. Eur J Neurosci 7:1773-90.

Kang H, Schuman EM (1995) Long-lasting neurotrophin-induced enhancement of synaptic transmission in the adult hippocampus. Science 267:1658-1662.

Katz LC, Shatz CJ (1996) Synaptic activity and the construction of cortical circuits. Science 274:1133-1138.

Linden DJ, Guillery RW, Cucchiaro J (1981) The dorsal lateral geniculate nucleus of the normal ferret and its postnatal development. J Comp Neurol 203:189-211.

Liu G, Tsien RW (1995) Properties of synaptic transmission at single hippocampal synaptic boutons. Nature 375:404-408.

Mason CA (1982a) Development of terminal arbors of retinogeniculate axons in the kitten: I. Light microscopical observations. Neuroscience 7:541-559.

McBain CJ, Dingledine R (1992) Dual-component miniature excitatory synaptic currents in rat hippocampal CA3 pyramidal neurons. J Neurophysiol 11:72-84.

McBain CJ, Dingledine R (1993) Heterogeneity of synaptic glutamate 
receptors on CA3 stratum radiatum interneurones of rat hippocampus. J Physiol (Lond) 68:16-27.

McCormick DA, Pape HC (1988) Acetylcholine inhibits identified interneurons in the cat lateral geniculate nucleus. Nature 334:246-248.

McCormick DA, Prince DA (1987) Post-natal development of electrophysiological properties of rat cerebral cortical pyramidal neurones. J Physiol (Lond) 393:743-762.

Meiri U, Rahamimoff R (1971) Activation of transmitter release by strontium and calcium ions at the neuromuscular junction. J Physiol (Lond) 215:709-726.

Miledi R (1966) Strontium as a substitute for calcium in the process of transmitter release at the neuromuscular junction. Nature 212:1233-1234.

Morishita W, Alger BE (1997) Sr2+ supports depolarization-induced suppression of inhibition and provides new evidence for a presynaptic expression mechanism in rat hippocampal slices. J Physiol (Lond) 505:307-317.

Oliet SH, Malenka RC, Nicoll RA (1996) Bidirectional control of quantal size by synaptic activity in the hippocampus. Science 271:1294-1297.

Paulsen O, Heggelund P (1994) The quantal size at retinogeniculate synapses determined from spontaneous and evoked epscs in guinea-pig thalamic slices. J Physiol (Lond) 480:505-511.

Penn AA, Riquelme PA, Feller MB, Shatz CJ (1998) Competition in retinogeniculate patterning driven by spontaneous activity. Science 279:2108-2112.

Perez Velazquez JL, Carlen PL (1996) Development of firing patterns and electrical properties in neurons of the rat ventrobasal thalamus. Brain Res Dev Brain Res 91:164-170.

Ramoa AS, McCormick DA (1994a) Developmental changes in electrophysiological properties of LGNd neurons during reorganization of retinogeniculate connections. J Neurosci 14:2089-2097.

Ramoa AS, McCormick DA (1994b) Enhanced activation of NMDA receptor responses at the immature retinogeniculate synapse. J Neurosci 14:2098-2105.

Ramoa AS, Prusky G (1997) Retinal activity regulates developmental switches in functional properties and ifenprodil sensitivity of NMDA receptors in the lateral geniculate nucleus. Brain Res Dev Brain Res 101:165-175.

Rocha M, Sur M (1995) Rapid acquisition of dendritic spines by visual thalamic neurons after blockade of $N$-methyl-D-aspartate receptors. Proc Natl Acad Sci USA 92:8026-8030.

Rossner S, Kumar A, Kues W, Witzemann V, Schliebs R (1993) Differential laminar expression of AMPA receptor genes in the developing rat visual cortex using in situ hybridization histochemistry. Effect of visual deprivation. Int J Dev Neurosci 11:411-424.

Scheetz AJ, Constantine-Paton M (1994) Modulation of NMDA receptor function: implications for vertebrate neural development. FASEB J $8: 745-752$.
Shatz CJ (1990) Impulse activity and the patterning of connections during CNS development. Neuron 5:745-756.

Shatz CJ, Stryker MP (1988) Prenatal tetrodotoxin infusion blocks segregation of retinogeniculate afferents. Science 242:87-89.

Sherman SM, Spear PD (1982) Organization of the visual pathways in normal and visually deprived cats. Physiol Rev 62:738-855.

Shi J, Aamodt SM, Constantine-Paton M (1997) Temporal correlations between functional and molecular changes in NMDA receptors and GABA neurotransmission in the superior colliculus. J Neurosci 17:6264-6276.

Sillito AM, Murphy PC, Salt TE, Moody CI (1990) Dependence of retinogeniculate transmission in cat on NMDA receptors. J Neurophysiol 63:347-355.

Soltesz I, Mody I (1995) Ca(2+)-dependent plasticity of miniature inhibitory postsynaptic currents after amputation of dendrites in central neurons. J Neurophysiol 73:1763-1773.

Spigelman I, Zhang L, Carlen PL (1992) Patch-clamp study of postnatal development of CA1 neurons in rat hippocampal slices: membrane excitability and $\mathrm{K}^{+}$currents. J Neurophysiol 68:55-69.

Staley KJ, Mody I (1991) Integrity of perforant path fibers and the frequency of action potential independent excitatory and inhibitory synaptic events in dentate gyrus granule cells. Synapse 9:219-224.

Stern P, Edwards FA, Sakmann B (1992) Fast and slow components of unitary EPSCs on stellate cells elicited by focal stimulation in slices of rat visual cortex. J Physiol (Lond) 449:247-278.

Stryker MP, Harris W (1986) Binocular impulse blockade prevents the formation of ocular dominance columns in cat visual cortex. J Neurosci 6:2117-2133.

Stryker MP, Zahs KR (1983) ON and OFF sublaminae in the lateral geniculate nucleus of the ferret. J Neurosci 3:1943-1951.

Sutton JK, Brunso-Bechtold JK (1991) A Golgi study of dendritic development in the dorsal lateral geniculate nucleus of normal ferrets. J Comp Neurol 309:71-85.

Sutton JK, Brunso-Bechtold JK (1993) Dendritic development in the dorsal lateral geniculate nucleus of ferrets in the postnatal absence of retinal input: a Golgi study. J Neurobiol 24:317-334.

Turrigiano GG, Leslie KR, Desai NS, Rutherford LC, Nelson SB (1998) Activity-dependent scaling of quantal amplitude in neocortical neurons. Nature 391:892-896.

Warren RA, Jones EG (1997) Maturation of neuronal form and function in a mouse thalamo-cortical circuit. J Neurosci 17:277-295.

Weber AJ, Kalil RE (1987) Development of corticogeniculate synapses in the cat. J Comp Neurol 264:171-192.

White CA, Sur M (1992) Membrane and synaptic properties of developing lateral geniculate nucleus neurons during retinogeniculate axon segregation. Proc Natl Acad Sci USA 89:9850-9854. 